\title{
Computer-assisted Language Learning in Georgia
}

\author{
Maia Gurgenidze
}

\begin{abstract}
This article is about computer/software assisted English language learning. The aim of this article is to provide an overview on what new technologies are in the world in this direction and what kind of benefits it could have if implemented in Georgia. It will argue that incorporating existing and creating new technologies in English language teaching is of crucial importance for developing English language teaching and learning. Firstly, this article will discuss the process of learning a language, where the importance of some aspects/activities will be highlighted. Secondly, the way new technologies support/make it easier to happen in the classroom environment, will be analyzed. This part will also show technologies that concenrate on aiding teaching another language, that could be useful for English language teaching as well. Thirdly, the benefits of bringing these new technologies, that this article will talk about, to Georgian classrooms, will be discussed.
\end{abstract}

Keywords - Computer-assisted Language, Learning.

\section{INTRODUCTION}

In order for one to be able to communicate properly in a particular language, one has to have a sufficient lexical ability. Thus, learning a language requires memorizing and getting oneself accustomed with new words, because this is the first step towards speaking a new language. Even if one knows all the elements of the grammar of a particular language, one will never be able to speak a language if one does not have a good command of the lexical aspect of this language. Based on this assumption, the primary goal of a language is to help learners memorize and get accustomed with new words and expressions, in order to let them practice in using them in real life and achieve the main goal of learning a new language - to communicate (Godwin-Jones, 2010).

A very common way of teaching a new language and in particular, new words, is through context, by asking learners to read a passage, identify new words and then find the meanings of these new words.This is usually carried out using a textbook, which introduces new words unit by unit through texts. At the end of every text there is a list of all the new words with the meaning of these words on the other side of the list. Students have a chance to go directly to the list and try to memorize the words (which is what usually happens in real life scenario), which makes the text useless, as students usually

Maia Gurgenidze, Professor, Ivane Javakhishvili Tbilisi State University, Tbilisi, Georgia prefer to use these words in the context they prefer - they are more interested in, and not in the one that the textbook provides. This kind of free thinking and the desire to think freely in classrooms started to develop in the 20th century, but this article will not ponder the reasons right now. Another very common way of teaching new words is the use of flashcards. However, new technologies make these techniques and ways obsolete. There is a technology that allows a language learner to check the meaning of a particular word by clicking on it through the software one is using for reading a particular text. Thus, one does not need to wait for the text to finish in order to get the meaning of new words. Also, one does not need flashcards, as the software has the ability to link the meaning of a particular word to the internet, which provides much richer resource for getting the meaning than a picture on a flashcard (Kuo and Hopper, 2004).

There is some schoalrly work done, which states that individuals working together can aid their language acquisition (Horst, Cobb, and Nicolae, 2005; Jones, 2006). This approach is based on the most important aspect of language learning, that also represents the goal of the process - communication. If one is able to express an idea or a desire with newly acquired words and phrases, this helps one to memorize new words better than just by memorizing it with the texts and passages provided through textbooks. In this way, a learner makes these words much more personal to onself by using them to describe something that one want to communicate with another. Thus, using the skill for which one learns another language as a practice tool for acquiring new words, can be very useful and psychologically beneficial for a learner, as one can see what progress one has right after the intorduction of new words (Godwin-Jones, 2010).

Another approach is the attribution of the meaning of new words to something personal in one's own mind. For example, one might associate an apple with a basket in one's kitchen, because one always sees an apple in the basket there. For this person, basket can be a trigger/hook to remembering the word - apple. Thus, when one tries to remember the word apple, one sees the word and a picture of a basket in one's mind and remembers the word 'apple' in this way. This is the technique employed by Cicero and other prominent orators and scholars in ancient times for remembering speeches and knowledge (Godwin-Jones, 2010).

There is a very interesting approach in learning Japanese characters formulated by James Heising. His method is very 
popular among Japanese language learners as it involves learning the Kanji characters by deconstructing each one and attributing to each part a specific meaning. Thus, learners hear a particular 'story' on each of the character, which helps them to memorize each one. More importantly, creating a new or using an existing story on a particular character makes their recognition easier. For learners who have never dealt with the characters before, is extremely difficult to differentiate and remember between different characters. Using a story as a basis for their easier recognition is a useful tool. This method deals with characters as individual entities. As people get closer by getting to know more about each other, it makes recognizing and remembering characters easier by 'connecting' with them through particular stories. If learners are allowed to connect the characters with something they associate them with, the learning process will become more enjoyable and personal, that will aid one in the learning process (Kuo and Hooper, 2004).

Using stories in learning a language is also used in English language teaching, where a particular program allows learners to receive more information behind the idioms and expressions (Boers, Demecheleer, and Eyckmans, 2004). The program is called Idiomteach, that aims to let students think about the meaning of a particular idiom, help one to create a background story on it and through this, aid its memorization (Loucky, 2006). This strategy is useful in many respects - to memorize a word, image and anything that is used for English language learning.

There is also a very useful way of learning a new language apart from using existing or new stories for remembering new words and expressions. Visual aid is provided in this case, where learners can use particular programs and apps which help them to conceptually map them, by linking a particular word or an expression to many related words and expressions. A learner has a chance to visually see a particular word or an expression in a context of words and expression that either have a similar meaning or are usually used in the same context (Bahr and Dousereau 2001). One program is created by Tuft University and is called VUE - Visual Understanding Environment. This program is created in order for leaners and teachers to have a tool which can link different visual material to particular words and expressions online. This makes the mapping of the meanings of different words and expressions with visual material online a lot easier. One can visually show similarieties and differences with visual material without the pressure of imagining and creating a story. Visual material aids one's imagination and helps a learner deepen and enrich one's visual knowledge.

A very useful tool is an electronic dictionary, which substituted the printed dictionary. Previously, an individual had to look up for a word manually in the printed version and check different pages for the word one was looking for. This was changed with the online database that has all the words with their meanings online - readily available for the ones who need to check the meaning of a word. They can type in the word they are looking for and the meaning momentarily appears. Lots of time has been saved and the process of finding the meaning of a word became a lot easier. This process involves finding the meaning of a new word, to learn something new, and the time needed for it was reduced. Thus, making dictionaries available online made the learning process much faster and easier, which can be stated that it also made it much more enjoyable than it previously was (Horst, Cobb, and Nicolae, 2005).

Another version of online dictionaries is the software that allows a reader to check the meaning of a word by just clicking on it in the text. The clicking is then followed by the pop-up window that shows the meaning of the word. The learning process was made even more efficient by allowing readers to check for the meaning of a new word right in the text and not wasting some time by closing the electronic text, opening a browser and trying to find the meaning of a word online. As the word becomes faster and more globalized, the learning and searching process showed be paced in a similar fashion (Horst, Cobb, and Nicolae, 2005).

There are some developments happening in Georgia in this respect, but it has to be stated that there can be done more in order to make the learning process more easier and efficient. English language teaching involves online platform - My English Lab, that has activities, tests and marking software online, available for all the students all the time. This allows students to do activities and develop English language skills any time they desire and then get the scores momentarily. This is an online work book where students do homeworks that teachers assign to them. Every level has its own activities and tests. However, it lacks several functions that were mentioned in this essay. It does not have the function of looking up for a word in the text by just clicking on it; it does not provide the chance for students to associate different words and letters to something personal to the learners; It does not provide the etimology of different phrases and words. It only provides activities, which was aimed to change the printed version of a work book. There is growing demand for online platforms such as this in Georgia, as learners see the benefits and effectiveness of an online workbook. Thus, a better and more sofisticated version of English language teaching can come handy in Georgia.

New online teaching material can also develop Georgian schools, where if all the schools are equipped with new computers or a computer lab is created at schools, which would allow pupils to access it for language learning classes, new platforms and softwares could be bought for teaching English, instead of buying textbooks every single year for every single pupil. This would make this area a lot cheaper as the government only has to pay once - for computers, that will allow all the available online workbooks and textbooks to be accessed in these labs. The government will not have to buy printed versions of the textbooks every single year. The administration and transportation costs will also be reduced. The marking process will become a lot easier as the 
program/software will provide the answers momentarily. All the benefits of online learning will be realized with all the tools that aid learners to learn new material. Thus, if there is a software or a work book online that can be used in English language learning process, there is a chance that the government reduces the expenses of providing all the textbooks for all the students by spending a single fee of creating computer labs at every school (with their maintenance, which will be a continuous fee) that will make the access and usage of online leaching materials available for teaching. They will not have to pay for a printed copy every single textbook and workbook for pupils, they will only have to pay for the software, that will reduce the fee of buying all the books, with less administration and no transportation needed for it.

This article was about the role of new technologies in assisting English language teaching and learning. It discussed several examples and provided their advantages over the previously existing material, where it was stated that new technologies made the learning process a lot easier and faster. Due to the fact that technological development and globalization necessitates all the aspects to be carried out in a lot faster way, there is a growing demand for faster learning process. There is a limited number of new technologies available in Georgian English language teaching environment, which has to be enriched in order to keep up with the development of the world. It will also be beneficial in other respects too, such as - making the teaching process more economically viable. There can be a nostalgic feel to reading a physical book, but this does not translate to the teaching, as there is absolutely no need for a printed textbook if there is an online version, where everything can be connected to the internet and every single piece of information available in just a second. The process can also involve other aspects of learning and teaching that was not possible with physical textbooks - showing videos in the same place one reads a text, electronic dictionary right next to the task where learners are not tested on vocabulary and are tested in critical thinking, and etc. Thus, in the developing word, incorporating new technologies is of vital importance in Georgian English language learning enviroments.

\section{REFERENCES}

[1] Bahr, G. S., and Dansereau, D. F. (2001) 'Bilingual Knowledge Maps (BiK-Maps) in Second-Language Vocabulary Learning', The Journal of Experimental Education, Vol. 70, No. 1, pp. 5-24; https://doi.org/10.1080/00220970109599496

[2] Boers, F., Demecheleer, M., and Eyckmans, J. (2004) in Bogaards, P., and Laufer, B., Vocabulary in a Second Language: Selection, Aquisition and Testing, (Amsterdam: John Benjamins);

[3] Godwin-Jones, R. (2010) 'Emerging Technologies From Memory Palaces to Spacing Algorithms: Approaches to Second-Language Vocabulary Learning', Language Learning and Technology, Vol. 14, No. 2 (June) pp. 4-11;

[4] Horst, M., Cobb, T., and Nicolae, I. (2005) 'Expanding Academic Vocabulary with an interactive on-line database', Language Learning and Technology, Vol. 9, No. 2, pp. 90-110;

[5] Kuo, M., and Hooper, S. (2004) 'The Effects of visual and verbal coding mnemonics on learning Chinese characters in computer based instruction', Educational Technology Research and Development, Vol. 52, No. 3, pp. 23-38; https://doi.org/10.1007/BF02504673

[6] Loucky, J. (2007) 'Maximizing Vocabulary Development by Systematically Using a Depth of Lexical Processing Taxonomy, CALL Resources, and Effective Strategies', CALICO Journal, Vol. 23, No. 2, pp. 363-399; 